\title{
PISTAS PARA UM AGIR CRIANÇÁVEL NAS EXPERIÊNCIAS DE CONFLITO
}

\author{
FACTORS FOR A 'CHILDNESS' EXPRESSION IN \\ CONFLICTUAL EXPERIENCES
}

\section{PISTAS PARA UNA ACTUACIÓN NIÑABLE EN LAS EXPERIENCIAS DE CONFLICTO}

\begin{abstract}
Maria Cristina G. Vicentin ${ }^{1}$; Gabriela Gramkow ${ }^{2}$
RESUMO

O campo discursivo da "indisciplina", do "conflito" e da "violência na escola" tem sido estratégico para colocar em análise as tensões e os paradoxos que se efetuam no cotidiano escolar, especialmente no tocante às relações de poder adulto-criança. Nesse âmbito, temos visto serem privilegiadas respostas pautadas em lógicas individualizantes, punitivas, judicializantes e medicalizantes que fragilizam a sustentação dos espaços públicos na escola e o exercício coletivo e compartilhado de análise da produção desses modos de funcionamento escolar e da variabilidade e singularidade de seus processos. Este artigo busca discutir algumas pistas ético-políticas para dispor no território escolar, em diálogo com aportes da sociologia da infância, da psicanálise e da análise institucional, visando a experimentação de outras temporalidades e outros sentidos para as experiências conflituosas, tendo como nortes a legitimidade do agir político de crianças e adolescentes e a utopia ativa de uma escola justa e democrática. Para tanto, nos valeremos da apresentação de vinhetas do cotidiano escolar que nos permitirão evidenciar a potência analisadora das insurgências de crianças e adolescentes assim como certas linhas de produção do descriançável ou do criançável.
\end{abstract}

PALAVRAS-CHAVE: Infância. Conflito e educação. Escola. Sociologia da infância.

\begin{abstract}
The discursive field of indiscipline, conflict and violence at school has been strategic to analyze the tensions and the paradox that exist in the school environment, specially towards the power relation between adults and children. In this scope, we have seen more commonly actions that favors a logic that is individualistic, punisher, judicialized and medicalized, that fragilizes the maintenance of public spaces at schools as well as the shared and collaborative exercise of the analysis of the production of these school functional modes and its processe's variabilities and singularities. This article aims to discuss some ethic-political factors for use in the school scope, dialoguing with inputs from childhood sociology, psychoanalysis and institutional analysis, to promote the experimentation of other temporalities and meanings for conflictual experiences, having as a north the legitimacy of the political expression of a child or an adolescent and the active utopia of a just and democratic school. To achieve this goal, it will be employed sketches that will present the school quotidian and
\end{abstract}

\footnotetext{
${ }^{1}$ Doutora - Psicologia (Psicologia Clínica) - Pontifícia Universidade Católica de São Paulo (PUC-SP). São Paulo, SP - Brasil. Professor Doutor - Faculdade de Ciências Humanas e da Saúde da Pontifícia Universidade Católica de São Paulo (PUC-SP). São Paulo, SP. Brasil. E-mail: mvicentin@pucsp.br

2 Doutora - Psicologia (Psicologia Clínica) - Pontifícia Universidade Católica de São Paulo (PUC-SP). São Paulo, SP. Brasil. Professor Doutor - Faculdade de Ciências Humanas e da Saúde da Pontifícia Universidade Católica de São Paulo (PUC-SP). São Paulo, SP - Brasil. Pós-doutoranda - Faculdade de Educação da Universidade de São Paulo (USP). São Paulo, SP - Brasil E-mail: ggramkow@pucsp.br
}

Submetido em: 08/10/2017 - Aceito em: 29/12/2017

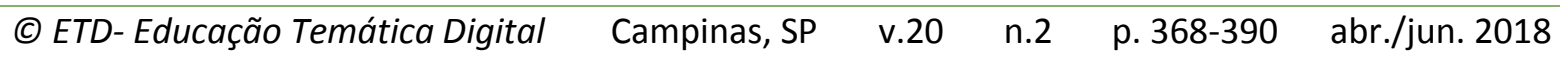


will allow us to evidentiate the analitical power of the insurgence of the child or adolescent as certain production lines of 'childness' and 'unchildness'.

KEYWORDS: Childhood. Conflict and education. School. Childhood Sociology.

\section{RESUMEN}

El campo discursivo de la indisciplina, de lo conflicto y de la violencia en la escuela es estratégico para poner en análisis las tensiones y las paradojas del cotidiano escolar, especialmente en lo que se refiere a las relaciones de poder entre el mundo adulto y el infantil. En ese ámbito son privilegiadas, en general, las respuestas pautadas en lógicas individualizantes, punitivas, judicializantes y medicalizantes que fragilizan la sustentación de los espacios públicos en la escuela, como también el ejercicio colectivo y compartido del análisis de la producción de esos modos de funcionamiento escolar y de la variedad y la singularidad de sus procesos. Este artículo pretende discutir algunas pistas ético-políticas para ofrecer al territorio escolar, en diálogo con los aportes de la sociología de la infancia, psicoanálisis y análisis institucional, objetivando ensayar otras temporalidades y sentidos para las experiencias conflictivas, legitimando la actuación política de infantes y adolescentes y la utopía activa de una escuela justa y democrática. Para tanto, nos valdremos de la presentación de escenas del cotidiano escolar que nos permitirán poner en evidencia la potencia analizadora de las insurgencias de infantes y adolescentes así como ciertas líneas de producción de lo 'niñable' o de lo ‘noniñable'.

PALABRAS CLAVE: Infancia. Conflicto y educación. Escuela. Sociología de la infancia.

\section{INTRODUÇÃO}

Uma perspectiva recorrente na construção de uma história do governo ${ }^{3}$ da infância e adolescência no Brasil privilegia, no que se refere à regulação das relações entre crianças e adolescentes e o mundo adulto, a narrativa da passagem da "doutrina da situação irregular", que efetua a tutela e a "menorização" de crianças e adolescentes, para a "doutrina da proteção integral", que considera crianças e adolescentes enquanto sujeitos de direitos, como seres humanos em condição peculiar de desenvolvimento e com prioridade absoluta para a promoção, proteção e defesa de seus direitos.

Ao longo do século XX, teve início a construção de uma nova sensibilidade e uma nova atitude em relação às crianças. Isso ficou especialmente visível na promulgação de legislações em defesa dos direitos das crianças ${ }^{4}$ e na constituição de políticas e sistemas de

\footnotetext{
${ }^{3}$ Ao falar de governo, não nos referimos aos regimes políticos, mas às modalidades de regência/regulação das condutas dos indivíduos, seja quanto às racionalidades ou quanto às tecnologias acionadas nessa gestão. (cf. FOUCAULT, 1999; 2001, 2008).

${ }^{4}$ Esse consenso social em torno da ideia moderna de infância, ou sua definição normativa, foi sendo particularmente construído através de sucessivos documentos legais que regularam a vida das crianças e padronizaram os modos de relação entre o Estado, as famílias e as crianças e entre estas e os adultos. Tal construção culminou na Convenção Internacional sobre os Direitos das Crianças (CDC), de 1989, instrumento de direitos humanos mais ratificado em escala mundial, e que se tornou uma das expressões mais significativas da globalização política e cultural de um determinado modelo de infância. (MARCHI, 2007; ROSEMBERG; MARIANO, 2010).
}

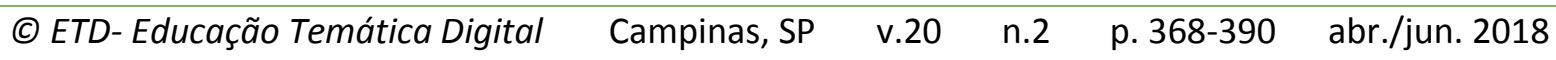


defesa e garantia de direitos com consequências concretas para as condições de vida e de desenvolvimento de crianças e adolescentes.

No entanto, o consenso social da infância como fase longa de proteção e socialização presente nessas mudanças é construção de uma sociedade desigual. Como sinaliza Marchi (2007), as crianças que estão "fora da norma da infância" estão, de alguma maneira, excluídas da promessa da modernidade da infância: desconsideradas de sua condição infantil, são muitas vezes tematizadas como expressão de uma "patologia social", senão mesmo de uma "patologia ontológica".

Assim, tais marcos legais, que resultam do jogo de tensões e coalizões entre diversos atores sociais (ROSEMBERG \& MARIANO, 2010), convivem, no caso brasileiro, com a longa história de institucionalização, criminalização e tutela da criança ou, como aponta Caldeira (2000), são expressão simultaneamente da expansão dos direitos de cidadania e do seu desrespeito.

Desse modo, tal como Arantes (2012) propõe no caso do Brasil, entendemos a noção de proteção como o princípio ético que melhor corresponde às lutas, histórias e possibilidades atuais. Assim mesmo, é necessário pensar e analisar os efeitos das legislações e das políticas, tanto no que diz respeito ao lugar social de crianças e adolescentes e às discriminações etárias e de gerações a que estão expostos (MELO, 2008), como no que se refere ao lugar do conflito na relação adulto-criança, uma vez que entendemos as relações de idade como relação de poder (ROSEMBERG, 1997).

Trata-se, portanto, de arguir as lógicas tutelares, moralistas e autoritárias que se atualizam nas noções de proteção e de desenvolvimento, as quais estão na base das políticas dirigidas à infância e à adolescência (ARANTES, 2012; ROSEMBERG \& MARIANO, 2010) e configuram, na perspectiva que vamos adotar aqui, um agir descriançável. Isto é, um agir que produz um sufocamento dos processos de abertura, acolhimento e invenção de territórios com as crianças e adolescentes, na medida em que está pautado numa lógica adultocêntrica e normalizadora que caracteriza o "dispositivo da infantilidade" (CORAZZA, 2000). Por meio desse dispositivo, constituído na Modernidade ${ }^{5}$, a criança vai sendo instituída como um problema econômico-político, uma preocupação médico-moral, um encargo pedagógico, um objeto de conhecimento das Ciências Humanas e Sociais que deve

\footnotetext{
${ }^{5}$ De acordo com Foucault $(2008,2001)$, foi a partir do século XVIII, na Europa, que a arte do governo alcançou um desenvolvimento expressivo, caracterizando-se pela emergência da população como objeto privilegiado de governo, isto é a defesa da vida e seu bem-estar. As crianças passam a ser alvo privilegiado dessas operações que administram corpos e visam a gestão calculista da vida, tornando-se objeto de operações políticas, de intervenções econômicas, de campanhas ideológicas de moralização e de escolarização.
}

(C) ETD-Educação Temática Digital Campinas, SP $\quad$ v.20 $\quad$ n.2 $\quad$ p. $368-390 \quad$ abr./jun. 2018

[370] 
ser interrogado, investigado, mensurado, classificado e normalizado. Com isso, as crianças passam a ser sujeitadas por um conjunto de instituições disciplinares que circunscrevem o âmbito das experiências próprias de cada idade e descrevem não só os cuidados de que devem ser objeto, como as operações necessárias para garantir sua transformação em cidadãos úteis e ajustados à ordem social e econômica vigente. (DONZELOT, 1986; CORAZZA, 2000).

É desse tempo histórico a origem da psicologia do desenvolvimento que se vincula à classificação e mensuração de condutas, estabelecendo e consolidando as práticas escolares de classificação e ordenação das crianças conforme seus desempenhos (CASTRO, 1998). Nas palavras desta autora:

[...] o processo de escolarização da infância trouxe consigo a "infância sob medida", num duplo sentido: em primeiro lugar, a revelação de uma infância segundo os cânones do saber "especializado", alinhada dentro do balizamento psicométrico relativo às habilidades e aptidões, ou seja, uma infância "especificada" no seu trajeto; em segundo lugar, uma infância cujo trajeto estava especificamente prescrito e explicitado, onde algumas sequências seriam melhores do que outras; enfim, uma infância normatizada (p. 32).

Para Donzelot (1986), tais objetivos de natureza sanitária, pedagógica e política visavam também "reduzir a capacidade sociopolítica dessas camadas, rompendo os vínculos iniciáticos adultos/criança, a transmissão autárquica dos saberes práticos, a liberdade de movimento e de agitação que resulta do afrouxamento de antigas coerções comunitárias" (p.76). Ou seja, esse dispositivo constituiu a particularidade da infância, mas às custas de situar a criança no centro de potentes modos de codificação. Daí a proposição de Godard: "as crianças são prisioneiros políticos" (apud DELEUZE, 1992, p. 55).

Diferentes estudiosos têm sinalizado ainda que, a despeito da construção da criança como sujeito de direitos, os fundamentos políticos e jurídicos que influenciaram essa mutação ainda se voltam mais para a garantia do direito de proteção e cuidado do que para a legitimação da sensibilidade e perspectiva da criança em suas singulares relações com os adultos. Os estudiosos sugerem que é necessário refletir acerca das consequências dessa atitude protecionista em termos políticos, na medida em que esse discurso fomenta uma condição de dependência e de incapacidade sociopolítica da criança e dos adolescentes (CASTRO, 2001; ARANTES, 2012). 
Ao introduzirmos aqui um crivo analítico criançável-descriançável (VICENTIN, 2016) não advogamos um modo-criança universal ${ }^{6}$, muito menos estamos falando de um infantilismo ou infantilização (que atravessa os adultos também). Trata-se de um ethos em relação às crianças e aos adolescentes que pretende sustentar, na relação com as crianças, um agir criançável, pautado na abertura a situações e problemáticas que não estão dadas $a$ priori, mas que são produzidas nas relações, e que requerem a sustentação de territórios de convivência, a experimentação do pensamento e a intervenção contextualizada e coletivizada. Criançar é suspender o encadeamento extensivo, espacial e cronológico nos estados de coisas; é entrar no estado intensivo em que a própria vida se deixa tomar por "entre-tempos", por "entre-mundos", quando não se separa o corpo infantil de sua potência vital (ORLANDI, 2008).

Neste texto, buscamos apresentar algumas pistas ético-políticas visando a experimentação de outras temporalidades e outros sentidos na relação com as crianças e os adolescentes, especialmente quando das experiências de conflitos. Para tanto, nos valeremos da apresentação de vinhetas do cotidiano escolar, que nos permitirão evidenciar a potência analisadora das insurgências das crianças e adolescentes e de seus processos singulares de subjetivação, assim como certas linhas de produção do descriançável e/ou do criançável.

Desse modo, discutiremos, inicialmente, o exíguo lugar da criança e do adolescente como atores políticos e como protagonistas de conflitos; e, em seguida, apresentaremos algumas vinhetas de situações na escola pelas quais a gestão dos conflitos evidencia tensões que se dão entre a hipercodificação do adulto e o agir criançável.

\section{PROTEGER, PREVENIR, GERIR OS RISCOS: QUAL O LUGAR DO CONFLITO?}

Para a psicologia do desenvolvimento, comprometida com os valores da Modernidade, sob inspiração do lluminismo, a ideia da emancipação é central, inclusive com a aproximação das categorias criança e selvagem, que são entendidos como imaturos e nãodesenvolvidos (e, portanto, em um estado mais próximo de uma suposta natureza). Tal projeto emancipatório, instaurado especialmente ao final do século XIX, delineia a noção de desenvolvimento humano como sequencial, cujas fases são ordenadas conforme princípios

\footnotetext{
${ }^{6} \mathrm{O}$ conceito de infância é uma construção cultural relativa aos modos pelos quais cada formação sociohistórica organiza a reprodução de suas condições materiais e culturais de trabalho e de vida. Essa construção varia de sociedade para sociedade e em cada época histórica (ARIÉS, 1981; DONZELOT, 1986). Na perspectiva histórica que nos interessa, a constituição da infância e as inflexões e mudanças que aí se passam não constituem superações ou progresso. Consideramos que convivem diferentes "dispositivos" de governo da infância.
}

(C) ETD- Educação Temática Digital Campinas, SP $\quad$ v.20 $\quad$ n.2 $\quad$ p. 368-390 abr./jun. 2018 
de complexidade e aperfeiçoamento crescentes e cujo desdobramento se dará no futuro, em direção ao indivíduo autônomo, autossuficiente e universal. (CASTRO, 1998).

Nessa combinação das duplas forças de infantilização e adultização, a forma-infantil foi subjetivada como sujeito "carente, primitivo, secundário, incompetente, ignorante, incapaz, irracional, amoral, num espelho-simulacro do sujeito verdadeiro adulto" (CORAZZA, 2002, p. 200-201).

Além de se orientar por uma "estrutura de racionalização adulta permanentemente definida" (JENKS, 2002, p. 212), tal perspectiva, como apontam Rosemberg e Mariano (2010), adota uma concepção de infância a seu serviço. Isto é, que privilegia a reprodução social" e o pressuposto metateórico do equilíbrio: "Pouca atenção é dada à contradição e ao conflito: uma criança ou se conforma, ou é tida como desviante" (p. 694). Em decorrência do que, é frequente que a resistência de crianças e adolescentes em relação à sua esperada posição tutelada e submissa seja interpretada como mostra de desvio ou anormalidade.

Uma vez que, frente ao ideal normativo, teremos como efeitos hegemônicos o desvio ou a carência, e nunca o conflito, cabe apresentar como esse lugar pouco reconhecido do conflito tem comparecido no campo da infância e, mais especialmente, no campo da educação.

O caso dos adolescentes em conflito com a lei nos parece emblemático para este debate no qual a perspectiva do conflito é pensada, via de regra, em relação "à lei", mas que deve ser pensada também como conflito com a sociedade, seja na forma de uma "recusa recíproca de integração" (OLIVEIRA, 2001), seja como "indiscernibilidade entre protesto/revolta/luta por novos direitos" (VICENTIN, 2005); o que nos faz ressituar a violência/periculosidade/risco que recai sobre os adolescentes numa perspectiva política, ao contrário da criminalização ou da pacificação dessas dissidências.

No Brasil, a partir dos anos 2000, a efervescência das rebeliões e dos corpos dos adolescentes em luta nos internatos deu lugar a processos crescentes de patologização, acionando a "função psi" 8 (FOUCAULT, 2001) e articulando o direito à saúde à defesa social (ROSA \& VICENTIN, 2010; GRAMKOW, 2012).

\footnotetext{
${ }^{7}$ Tais críticas se consolidam nas décadas de 1980 e 1990 especialmente a partir dos Estudos Sociais sobre a Infância (na tradição anglosaxônica), ou Sociologia da Infância (na tradição francófona) que busca entender a infância como uma construção social; atacar o conceito de socialização da criança como inculcação, até então predominante e conceber a criança como ator social. (ROSEMBERG; MARIANO, 2010).

8 "Função psi" como o conjunto de agentes, discursos, instituições, objetos que operam processos de normalização com vistas à defesa e à proteção da ordem social. Portanto, função psicológica, psiquiátrica, psicopatológica, psicossociológica, psicocriminológica, psicanalítica etc. (FOUCAULT, 2001).
}

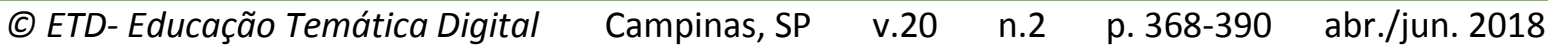


No campo da saúde mental, o enfrentamento à medicalização de crianças (com uma significativa interface com a escola) tem trazido importantes contribuições para a problematização da "psicologização dos conflitos sociais" (CRP, 2010). Aliás, como aponta Lobo (2015) em seus trabalhos sobre a Liga de Higiene Mental, além da "idiotia", "imbecilidade" e "debilidade", já se incluíam os indisciplinados ${ }^{9}$ na categoria psiquiátrica dos anormais, caracterizando-os, junto com os demais, pelo descontrole dos impulsos e pelos desvios de caráter. O grande problema das escolas não eram os "idiotas", facilmente deixados às margens dos bancos escolares, mas os que, uma vez inseridos em escolas regulares, geravam desordem e indisciplina, atrapalhando os professores e os demais alunos e gerando efeitos sobre a educação dos outros alunos.

Almeida (2017) discute, numa sociedade de normalização, o lugar dos diagnósticos propostos pelo Manual Diagnóstico e Estatístico de Transtornos Mentais (o DSM ${ }^{10}$ e seu objeto: os mental disorder) como racionalidades que compõem os modos de regulação da disorder dos vivos (dos distúrbios da ordem, do que está fora dos parâmetros) intensificando os processos de medicalização e mortificação no Brasil, especialmente os dirigidos às crianças e adolescentes.

Os mental disorder seriam uma extensão do poder psiquiátrico (FOUCAULT, 2006), ferramenta de um racismo ${ }^{11}$ moderno. Dentre essas "desordens", o chamado "transtorno de conduta" ou o "de oposição" destitui a legítima conflitualidade da criança em relação ao mundo adulto e sua potência disruptiva, uma vez que a criança rebelde, contestadora e indisciplinada coloca questionamentos ao jogo de forças estabelecido.

Os debates em torno da apatia, indisciplina, violência e conflitos na escola já contam hoje com um conjunto de estudos e debates consistentes (cf. AQUINO, 1996, 2016; GALVÃO, 2004; SCHILLING, 2008; 2014; SINGER, 2010), bem como com propostas de políticas e projetos que pretendem tomá-los como objeto de intervenção. A despeito da

\footnotetext{
${ }^{9}$ Conforme aponta Foucault (2001), o indivíduo a ser corrigido, ou "a criança indócil", é definido por sua incorrigibilidade, já que todas as técnicas familiares e educacionais fracassaram em relação a ele - o que o torna "inassimilável ao sistema normativo de educação" (p. 255): "cada vez que um indivíduo era incapaz de seguir a disciplina escolar ou a disciplina da oficina, ou a do exército, no limite a disciplina da prisão, a funçãopsi intervinha (...)" (FOUCAULT, 2006, p. 106).

${ }^{10} \mathrm{O}$ referido Manual emerge como um projeto de uma psicopatologia global que supõe uma ordem dos corpos e uma ordem das formas de adoecimento e, assim, cria normas para gerir, controlar e regulamentar a vida dos homens na sociedade, assim como novas racionalidades sobre o adoecer.

${ }^{11}$ Conforme Foucault (1999), o racismo estabelece uma lógica de poder que separa uma vida de outras vidas indesejadas de forma a conceber esta última como uma ameaça de risco à segurança daqueles que o poder se encarrega de fazer viver. O poder de matar e de expor à morte, não é "simplesmente o assassínio direto, mas também tudo o que pode ser assassínio indireto: o fato de expor à morte, de multiplicar para alguns o risco de morte ou, pura e simplesmente, a morte política, a rejeição, etc." (p. 306).
}

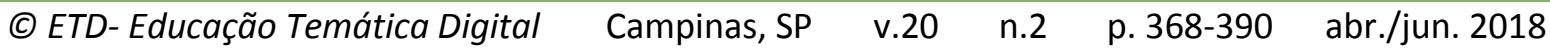


consistência conceitual, metodológica e ética desse debate, temos visto serem privilegiadas respostas pautadas em lógicas individualizantes, punitivas, judicializantes e medicalizantes que fragilizam a sustentação dos espaços públicos na escola, bem como o exercício coletivo e compartilhado de análise da produção desses modos de funcionamento escolar e da variabilidade e singularidade de seus processos.

Contribui para essa direção das ações o que Schilling (2014) sinaliza quanto ao retraimento social frente à sensação de insegurança e medo, face relativa ao discurso sobre a violência no cenário urbano. Edifica-se aí um movimento de ressegregação e contenção da infância e da adolescência em nome de sua proteção. Tal direção do governo das vidas não se propõe a analisar a produção da violência em sua multidimensionalidade, mesmo quando confrontado com os dados estatísticos dos homicídios de jovens (WAISELFISZ, 2014). As práticas de detecção precoce para prevenir e conter a violência estão sendo investidas não apenas no âmbito da gestão da criminalidade juvenil (acontecimento de expressão-limite da violência), como também no âmbito da gestão dos corpos de crianças e adolescentes na escola, na relação com o professor e seus pares. Mais ainda, vimos recentemente (em 2015 e 2016) com as ocupações nas escolas, realizadas pelos estudantes, lógicas de criminalização imperarem sobre as lógicas do conflito.

Vejamos como exemplo o caso do Sistema de Proteção Escolar da Secretaria de Educação do Estado de São Paulo (SPEC), implantado em 2010 (SEE, 2015) após divulgação de dois eventos ocorridos em escolas estaduais no estado, em $2008^{12}$ e em $2009^{13}$, ambos com presença da intervenção policial.

Segundo a Secretaria de Educação, o SPEC "consolida um conjunto de ações, métodos e ferramentas que visam a disseminar e articular práticas voltadas à prevenção de conflitos no ambiente escolar, à integração entre a escola e a rede social de garantia dos direitos da criança e do adolescente e à proteção da comunidade escolar e do patrimônio público" (SEE, 2015). O SPEC apresenta como suas principais ações os projetos de: 1. Professor Mediador Escolar e Comunitário (PMEC), 2. Vigilância Eletrônica, 3. Registro de Ocorrências Escolares (ROE) e 4. Atividades Formativas sobre a gestão de conflitos, a redução de vulnerabilidades e riscos no ambiente escolar, a prevenção de uso de álcool e

\footnotetext{
${ }^{12}$ Folha Online. Após briga e depredação, aulas em escolas de SP serão retomadas na próxima segunda. Folha de São Paulo, São Paulo, 13 de novembro de 2008. Disponível em:

http://www1.folha.uol.com.br/educacao/2008/11/467296-apos-briga-e-depredacao-aulas-em-escola-de-spserao-retomadas-na-proxima-segunda.shtml. Acesso em: 10/02/2015.

${ }^{13}$ Folha Online. "No meu tempo não tinha isso". Diz Serra sobre tumulto em escola. Folha de São Paulo, São Paulo,15 de maio de 2009. Disponível em:

http://www1.folha.uol.com.br/folha/educacao/ult305u566283.shtml Acesso em: 10/02/2015.
}

(C) ETD- Educação Temática Digital Campinas, SP $\quad$ v.20 $\quad$ n.2 $\quad$ p. $368-390 \quad$ abr./jun. 2018 
outras drogas, a prevenção ao "bullying" e a formação voltada para os direitos humanos e garantias fundamentais em parceria com a Unifesp, Instituto Sou da Paz, Ministério Público e Polícia Militar.

A formação, promovida pela Unifesp, a partir do Projeto Cuca Legal, pretendeu "oferecer estratégias de promoção em saúde mental e prevenção de transtornos mentais na escola" (SEE, 2015). Uma dessas estratégias é apresentar conceitos essenciais para identificar transtornos mentais como Ansiedade, Depressão, TDAH (transtorno de déficit de atenção e hiperatividade) e sensibilizar os professores "em relação às condutas necessárias para o trato com crianças e adolescentes que apresentam comportamento difícil ou mesmo de risco", contribuindo para a otimização do tratamento (CUCA LEGAL, 2015) e considerando que a prática de mapeamento precoce trabalha a favor da prevenção, produzindo a inclusão dos alunos.

Outra tática da prevenção, ainda em vigor, é o dispositivo do "Registro de Ocorrências Escolares", instrumento para registrar a indisciplina na escola e produzir informações confidenciais para os gestores ${ }^{14}$ da rede, a fim de mapear as situações de risco. Segundo a Secretaria de Educação, o ROE é uma ferramenta on-line que viabiliza o planejamento de ações preventivas desenvolvidas pela rede de proteção escolar - Polícia, serviços de saúde, Poder Judiciário e os serviços de proteção à criança e ao adolescente por meio de suporte técnico às escolas de maior vulnerabilidade.

Tibério (2011) sinaliza que a rede do SPEC é operacionalizada por gestores da área de segurança e nos convida a pensar que os conceitos de vulnerabilidade podem engendrar uma sofisticação das tecnologias de controle, já que demandam iniciativas preventivas para um futuro precocemente mapeado, exigindo e possibilitando táticas adiantadas para o presente. Essa antecipação do perigo autoriza a intervenção precoce de gestão dos corpos de todos e de cada um diante de um vir a ser da violência escolar.

De fato, como apontam Gonçalves e Sposito (2002), no início da transição democrática no Brasil, as políticas públicas de violência escolar reconheceram as práticas autoritárias nas escolas e sua dificuldade em atuar com elas, motivo pelo qual, adotaram práticas de caráter preventivo instituindo a participação dos pais e dos alunos nos processos de gestão da vida escolar. Porém, mais recentemente, a ação preventiva privilegia a

\footnotetext{
${ }^{14}$ Cabe ao ROE registrar: "I - ações ou situações de conflito ou grave indisciplina que perturbem sobremaneira o ambiente escolar e o desempenho de sua missão educativa; II - danos patrimoniais sofridos pela escola, de qualquer natureza; III - casos fortuitos e/ou de força maior que tenham representado risco à segurança da comunidade escolar; e IV - ações que correspondam a crimes ou atos infracionais contemplados na legislação brasileira". (SEE, 2015)
}

(C) ETD-Educação Temática Digital Campinas, SP $\quad$ v.20 $\quad$ n.2 $\quad$ p. $368-390 \quad$ abr./jun. 2018 
intervenção sobre os alunos, objetivados como protagonistas da criminalidade, individualizando um processo político.

Como sugere Singer (2010), os conflitos escolares compõem a vida escolar e é possível investir, no cotidiano, em práticas democráticas que promovam respeito e responsabilidade das crianças e dos adolescentes e que não recorram a uma autoridade moralizadora, mas apostem na invenção de caminhos de cuidado e acolhimento da criança e do adolescente neste encontro educador-educando.

Aquino (2016) corrobora essa aposta ético-política. Problematiza a indisciplina e afirma a concepção de conflitualidade em sua instabilidade, potência inventiva e enigma:

\begin{abstract}
(...) seria perfeitamente possível endereçar-se às idiossincrasias dos modos de viver/conviver aí em curso, não como pedido de socorro de uma instituição supostamente em perigo, porque continuamente arruinada por hábitos dissonantes de seus próprios protagonistas, mas como um mirante a partir do qual se pode flagrar a tessitura ético-política sempre acidentada, instável e, afinal, indeterminada das relações fáticas entre eles. 0 mundo escolar, pois, não como temeridade, inconveniência ou imperfeição, mas como permanente enigma. (AQUINO, 2016, p. 689).
\end{abstract}

Coincidimos também com Galvão (2004), que entende a escola como um espaço que, além de acolher conflitos próprios aos indivíduos nela reunidos e à sociedade em que ela se insere, favorece a ocorrência de conflitos cujos sentidos e fatores desencadeadores são ligados às especificidades dessa instituição de educação coletiva. Tais conflitos dizem respeito à complexa trama tecida por demandas infantis, condições institucionais, expectativas e concepções do educador. $E$, ainda que ligados a fatores exteriores à escola, 0 simples fato de se manifestarem lá (ou de lá não poderem se manifestar) já traz marcas do cotidiano escolar, assim como o marca.

Embora comumente encarado como negativo e destruidor, o conflito é necessário à vida, inerente e constitutivo, tanto da vida psíquica, como da dinâmica social. Sua ausência indica apatia, total submissão e, no limite, remete à morte. Sua não explicitação pode levar à violência. Mesmo que possa se confundir com ela, conflito não é sinônimo de violência. Violentos podem ser os meios de resolução ou os atos que tentam expressar um conflito que não pôde ser formulado, explicitado". (GALVÃO, 2004, p. 15)

Considerando que o reconhecimento dos conflitos e a disposição para compreender os sentidos que expressam são condição para que não se construa uma equação de igualdade entre conflito e violência, Galvão (2004) propõe a análise das situações de conflito no cotidiano escolar de forma a produzir um exercício de aprimoramento do olhar que envolve a implicação e, ao mesmo tempo, o recuo dos atores frente aos conflitos. A chave de análise que ela propõe é: em que situações o conflito indica movimento, crescimento? Em quais indica estagnação e se confunde com violência? Dito de outro modo: até que 
ponto os conflitos que eclodem no cotidiano escolar resultam de processos inerentes ao desenvolvimento ou podem ser tomados como indicadores de inadequações das práticas escolares, tendo em vista os recursos e possibilidades das crianças ou jovens? Nossa perspectiva pretende uma interrogação similar colocando em perspectiva a desqualificação sociopolítica da criança na situação de conflito e sugerindo algumas pistas para um agir que sustente a legitimidade da posição criança.

\title{
PISTAS PARA UM AGIR CRIANÇÁVEL ${ }^{15}$
}

\section{O conflito pede o exercício de um multilinguismo ${ }^{16}$}

\begin{abstract}
O Núcleo de Apoio e Acompanhamento para Aprendizagem (NAAPA) vai à escola observar uma criança etiquetada como agitada e agressiva. Ao chegarem à porta da unidade educacional, os participantes do Núcleo ouviram do lado de fora o gestor da escola gritando com uma criança que chorava: "chato, não aguento mais vê-lo todos os dias na minha frente" e "já não suporto ouvir seu choro". A equipe bate palmas para avisar sua chegada e o gestor suspende os gritos e acaricia a criança: "sente ali na minha sala, depois conversamos melhor". Após essa cena inicial, a equipe do NAAPA chega ao destino planejado: a sala de aula do garoto "agressivo". Durante as observações feitas na sala de aula, o garoto, apontado pela professora como o incontrolável, assiste ao filme proposto pela mesma, desenha com os colegas e, já à espera de sua mãe ao término da aula, brinca e se diverte. A ampliação dos olhares parece quebrar o feitiço do estudante "violento" - e, no dispositivo coletivo montado com a entrada de profissionais de apoio à escola, o criançar se produz.
\end{abstract}

Esta cena evoca o que aqui chamamos de multilinguismo como um exercício que valoriza a pluralidade das perspectivas e desmancha os riscos de uma sobrecodificação das formas singulares de expressão da criança na forma-adulta. A diferença de campos de percepção - a importância dessa diferença e do próprio diferir - revela-se um caminho interessante para pensarmos os dissensos entre o universo adulto e o infantil, suas mesclas e distanciamentos, bem como para analisarmos criticamente o predomínio do enfoque adultício.

\footnotetext{
${ }^{15}$ A pista do multilinguismo foi indicada em outros textos (VICENTIN, 1996; 2016) com outros propósitos e está aqui desdobrada em diálogo com o tema do conflito, agregando novas referências conceituais.

${ }^{16}$ Os casos-vinheta apresentados foram acompanhados em processo de supervisão nas práticas de estágio de estudantes de Psicologia da PUC-SP desenvolvidas no NAAPA pela professora Gabriela Gramkow; a narrativa foi produzida a partir de diferentes situações analisadas e compartilhadas nesse processo. O NAAPA (Núcleo de Apoio e Acompanhamento para Aprendizagem) da Secretaria Municipal de Educação de São Paulo, implementado em 2014, tem por objetivo garantir a proteção integral de crianças e adolescentes da rede municipal, romper com leituras individualizantes das situações e problematizar a medicalização da vida e a patologização da diferença no ambiente educativo, de forma que, por meio de casos individuais, seja possível o repensar das práticas institucionais.
}

(C) ETD- Educação Temática Digital Campinas, SP $\quad$ v.20 $\quad$ n.2 $\quad$ p. $368-390 \quad$ abr./jun. 2018 
Daniel Stern (1992), psicanalista e pesquisador norte-americano do desenvolvimento emocional de bebês, argumenta sobre a necessidade de ser bilingue no trato com a criança. Ele diz ter tido aos sete anos uma importante experiência: observando bebês na interação com os adultos, foi capaz de entender simultaneamente a linguagem do bebê e do adulto. Naquele momento, para ele, parecia óbvio que o bebê estava lá por inteiro, mas que o adulto não parecia entendê-lo de jeito nenhum. Ocorreu-lhe que ele estava em uma idade central, na qual ainda era bilíngue. Ao trabalhar posteriormente como psicanalista compreendeu que o bilinguismo seria uma ferramenta clínica importantíssima e vital para ele.

Seguindo essa intuição, buscamos em Ferenczi (1992) a noção de "confusão de línguas entre adultos e crianças". Para ele, a ternura é a tônica na infância, quando os desejos e as ações são consequência direta do disparar pulsional e do ritmo de cuidados estabelecido com os cuidadores. Ternura, nas palavras do autor, seria o amor objetal passivo (op. cit., p. 103), formando núcleos de subjetividade nos quais a discriminação entre sujeito e objeto ainda não se enrijeceram, e as identificações objetais só ocorrem como imitações e experimentações lúdicas. Já, na adultidade, a paixão é a língua que se destaca quando as atitudes passam a implicar intenções ocultas, muitas vezes para o próprio adulto. Isso traz fortes implicações quando as "intenções ocultas" ganham um caráter impositivo, opressor e inflexível.

Lourau (1991) chamará de "hipercomunicação adulto-criança" essa dimensão "terrível e deliciosamente obscura" na relação adulto-criança e ainda "mais obscura" na relação pedagógica pais/crianças, educadores/crianças; essa sobreimplicação imposta à criança pelo adulto, pela qual a criança fica sem voz e sem lugar, "inexistente" ou "fora do jogo", como um jogador de futebol que, durante uma partida, recebe do juiz três cartões amarelos. Como consequência, a criança passa a "submeter-se automaticamente à vontade do agressor, a adivinhar o menor de seus desejos, a obedecer esquecendo-se de si mesmas, e a identificar-se totalmente com o agressor" (FERENCZI, 1992, p. 102), ou seja, passa a reagir de maneira autoplástica, cortando e isolando em si elementos de sua fruição subjetiva e não mais agindo de maneira aloplástica, quando transforma o mundo - que acolhe suas intervenções afetivas - e é transformada por ele em uma mútua linha de metamorfose. Esses são casos extremos, mas nos ajudam a pensar contextos em que uma expressão agressiva e revoltosa é expressão legítima de um atravessamento de fluxos que insiste na instauração de um território existencial mais terno e menos opressivo.

A criança é elemento ativo da expressão de um mundo do qual os adultos também são resultado, e que se constitui não só de alegrias, como também de violências. Pensando 
dessa forma, a criança vai deixando de ser a vítima ou a incapaz. Sua pretensa precariedade é uma ilusão de déficit produzida por olhos armados, desapropriados da potência de perceber nos encontros com a criança um universo pleno e singular. Restituir à criança seu protagonismo instituinte pode fazer frente aos aspectos tristes da adultidade, de sua "madura - e por vezes desumana - humanidade". Crianças muito pequenas captam a atmosfera emocional dos adultos e se dispõem - ou não - a cuidar deles, quando assolados pela tristeza, a confusão ou o medo: são polos ativos da relação imprimindo sua marca, influência e humor desde cedo. Com essa perspectiva, complexificamos a relação e resistimos ao olhar hegemônico e reducionista de uma inaptidão da criança para imprimir seu volume afetivo nas relações, estando fadada ao desamparo e ao submetimento, aos desejos conscientes e inconscientes dos adultos.

Trata-se de agir por uma ampliação de perspectivas que suscitem intervenções que afetem o complexo criança-adulto-entorno, de forma a que a relação como um todo se desloque em direção a uma saúde possível, à captação de uma potência do criançar que não está podendo ocorrer, potência esta distribuída pelo coletivo de percursos afetivos vividos em uma relação, em uma família, em uma comunidade, em uma cultura, em uma época.

Agindo assim, acreditamos abrir a possibilidade para pensar as crianças como polos afetivos de uma relação intensa e intensiva, que pode engendrar a expansão vital ou a tristeza e a dor deste compósito singular "criança-adulto-entorno". O plano da prescrição de comportamentos adequados e desejáveis por si só não contempla a incontornável importância do acolhimento do que chamamos de criançar. Entendemos o bilinguismo não como a posse de dois sistemas de linguagem, mas como a capacidade de variação permanente que afeta cada sistema, impedindo-o de ser homogêneo e de se descolar de um plano de produção comum.

Queremos ressaltar que, garantida a integridade física e mental das crianças, é preciso reparar e apostar no espaço singular de jogo e invenção que abriga a relação entre adultos e crianças.

O conflito pede acolhida e a coragem de sua sustentação

O adolescente que convoca o NAAPA para atuar na cena da unidade educacional é do sexto ano do Ensino Fundamental. Considerado muito agressivo com os colegas, dá socos e chutes, e assedia as garotas. A escola relata que a mãe, durante uma advertência do estudante na escola, ao ser convocada a participar, ameaçou punir o filho, que gritava e chorava pedindo socorro. O NAAPA, em seu movimento inicial de rastreamento do conflito, realizou uma primeira ação de observação do processo de socialização do estudante. Ao chegarem à escola, surpreendentemente se depararam com um festival de dança. Nesse cotidiano

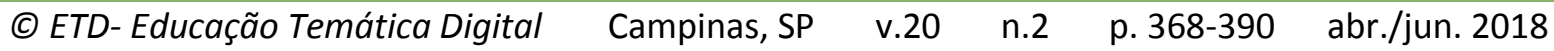


escolar, nota-se a aposta na dimensão participativa dos estudantes que promoveram um festival de dança; e o estudante em questão, no jogo musical com os seus pares, apresentava um outro território existencial diverso daquele enunciado em seu relatório, o do protagonista de conflitos. A despeito desse investimento presenciado pela equipe do NAAPA, que conforma outras possibilidades de acolhimento dos modos juvenis, a equipe, durante a observação das práticas escolares, também testemunhou o sufocamento dessa abertura quando a equipe gestora e o grupo de professores interromperam a festa. A gestão da escola argumentou que consideraram haver uso e possível tráfico de drogas durante a festividade, o que seria a motivação para o cancelamento do festival. Os adultos não suportaram a intensidade e a imprevisibilidade do evento e suspenderam a invenção promovida pelos jovens, que passaram a ser tratados sob o crivo da "indisciplina". Essa cena evoca a desqualificação da potência participativa dos jovens e a dificuldade da sustentação do conflito. Nesse contexto, o agir agressivo do aluno não pôde ser contornado com os sentidos do pertencimento, do enigma ou mesmo de uma demanda amorosa e a violência pôde ocupar o lugar do conflito.

A impactante presença dos adolescentes fazendo da escola um campo de "ocupação" e de "extensão" de seus territórios existenciais sugere que os corpos dos adolescentes protagonizam modos de ser e formas de resistência frente à cultura escolar, quando transpõem ou deslocam limites, configurando novos espaços de expressão e importantes campos de disputa pela construção de sentidos coletivos. Evidencia, também, que a escola pode ser espaço de acolhida e experiência desse deslocamento de fronteiras. No entanto, a resposta de interrupção da festa, tendo em vista a contenção do risco real ou potencial dos adolescentes, tomando a festa como problema sobre o qual é necessário intervir, faz do desejo intensivo uma zona permanente de periculosidade, cuja ameaça deve ser previamente evitada. Impede-se assim que a experiência ganhe consistência com base na reflexão sobre seus efeitos, sobre seu processo e sobre os conflitos que sua realização configuraram.

A capacidade de interrogar os modos de funcionamento dos grupos e das organizações sobre o sentido e os efeitos de sua ação faz da adolescência um agudo analisador do "socius" (LAPASSADE, 1973). Para que esse ato ganhe densidade analisadora e condições de constituição de uma experiência, é fundamental pressupor a legitimidade da ação do adolescente, bem como sustentar as ressonâncias, as dissonâncias e os vetores de conflito que ela produz, de forma a constituir um coletivo. A dimensão coletiva e as condições de produção do comum resultarão desse exercício de contração das heterogeneidades e das diferenças.

Tanto a omissão quanto a postura autoritária de diretores e professores têm efeitos na expressão de ações de violência nas escolas. A superação desse quadro está diretamente relacionada à capacidade que a escola demonstra ter para debater e enfrentar os problemas

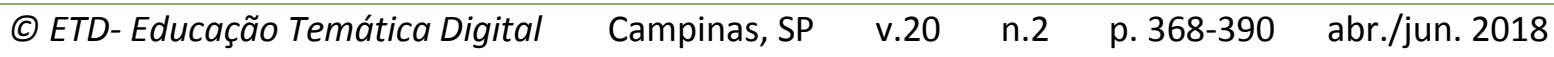


e os conflitos como uma situação comum a todos e que, por isso, necessita do apoio de todos para ser superada. Do mesmo modo, em situações de confrontos entre estudante e professor, assim como nos confrontos entre estudantes, quanto menor for o espaço de diálogo, quanto mais isolados estiverem de um campo de sustentação coletiva, maiores serão os riscos, para ambos, de serem envolvidos em um confronto violento. (ABRAMOVAY \& RUA, 2002).

Além disso, é fundamental estar atento aos modos de subjetivação singulares de crianças e adolescentes. Esse modo de ocupar freneticamente os lugares até desfigurá-los com desmesuras, o intensificar esses usos até serem temidos ou banidos é parte de um modo de posicionamento dos adolescentes, uma espécie de "inclusão às avessas" (DIÓGENES, 1998). Tal posição pode configurar um campo de potências, se agenciado com a escola interessada na vida, ou resultar em violências e entristecimentos, se a ação da escola for a de exercer total controle sobre o incontido de todo o vivo.

É a acolhida das diferentes posições em sua legitimidade e o jogo de suas diferenças e diferenciações que podem configurar um campo coletivo, nossa terceira pista.

\section{O conflito pede um agir coletivo}

O NAAPA foi chamado para acompanhar um adolescente após a agressão física contra uma professora. Em visita técnica à escola, um professor, referência para o estudante e para seu irmão, também estudante da mesma unidade educacional, relata que propôs a troca de sala entre os dois irmãos. A troca foi proposta para tentarem experimentar um novo encontro entre o estudante apontado como agressor e um outro educador. Nesse mesmo sentido, a professora apontada como vítima também poderia vivenciar uma outra experiência ao suspender momentaneamente as marcas da cena violenta vivida e se encontrar com o irmão do adolescente, incialmente forjado como o promotor da violência. Os professores e os dois irmãos-estudantes consentiram e acolheram a saída proposta. Esse educador-mediador do conflito enunciou sua identificação racial com o estudante negro e compartilhou sua história de vida, em que tinha vivido cenas muito semelhantes ao que esses dois irmãos-estudantes vivem. O professor mediou espontaneamente o conflito vivido entre sua colega professora e o educando e justificou que no cotidiano aproxima-se dos estudantes e dialoga sobre seus interesses e vivências, inclusive saindo dos muros da escola e produzindo encontros com os estudantes. Por exemplo, compartilhou que já tinha feito visitas a esse estudante agressor, fora da escola, em um semáforo onde o estudante atuava como malabarista. Nessa lateralização entre educadoreducando, ocorre uma suspensão da rigidez do encontro pedagógico e se possibilita a experimentação afetiva e de uma continência próxima e permanente, sustentada em uma intervenção coletiva.

A posição lateral do educador (em contraposição à sobrecodificação), a experiência de um território existencial compartilhado (que ativa processos de identificação professor-

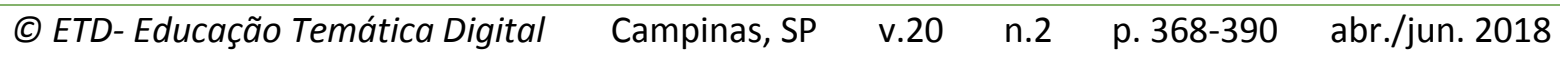


estudante, mas que abre outra perspectiva de leitura, exercitando o multiliguismo), em conjunto com a articulação de uma rede de sustentação na escola, sintetizam, numa ação, as duas pistas de que falamos acima e nos permite introduzir outra dimensão: a da rede. Isto é, de uma lógica que opõe ao "circuito de fluxos estáticos e labirínticos" - o qual condena os sujeitos a um desfecho do qual dificilmente escapariam - práticas que operam como "nós", constituindo diferentes e mutáveis desenhos dos projetos educativos (LISBOA, 2013).

A rede como forma de organização de pessoas, grupos e organizações que trabalham juntas contrapôs-se ao modo piramidal e centralizador de gestão e organização e surgiu no bojo das lutas autogestionárias, cogestionárias, das lutas democráticas: organização horizontal, sem comando nem mando, sem hierarquias nem exclusões, sem imposições nem proibições, na base da corresponsabilidade e da cooperação. Tomemos a definição proposta por Teixeira (2003): rede é uma multiplicidade conectada de agenciamentos heterogêneos. Isto é, o trabalho em rede pressupõe a aposta de que a diversidade proveniente de diferentes saberes e campos de experiências permite ampliar a leitura de uma situação e gerar novos recursos de ação. Trabalhar em rede é trabalhar convergentemente, mas não indiferenciadamente. Tanto mais diferenciados e heterogêneos os lugares da rede, mais rede. Dito de outro modo: se pensamos que rede é apenas um plano topológico, geográfico ou organizacional (por exemplo, de referência e contrarreferência, de fluxos), estamos produzindo um plano necessário, mas insuficiente. Nesse modo de pensar, estamos na multiplicidade conectada ou, ainda, na heterogeneidade. Mais do que isso: uma rede não deve apenas articular multiplicidades, deve também produzi-las.

É necessário incluir na rede a perspectiva da produção de sociabilidade, isto é, a "energia antropológica" dos laços sociais: conexões e agenciamentos; plano das relações quentes. Porque, caso contrário, temos vínculos ou relações sem consistência e sem potência. É no agenciamento, na conexão, que somos levados a diferir e a compor. Teixeira (2003) chama esse plano (referindo-se, no caso que analisa, às redes de trabalho em saúde) de redes de trabalho afetivo, no sentido de que o essencial nelas é, de fato, a criação e a manipulação de uma potência de afetar, isto é, a própria produção de redes sociais, de comunidades, de formas de vida, de produção de subjetividades (individuais e coletivas) e de sociabilidade.

Além disso, não basta que tenhamos redes de sociabilidade para constituir/suscitar a dimensão coletiva. Se não incluímos na própria rede os efeitos concretos que nossas intervenções vão provocando de forma a detectar a direção que essas conexões vão 
produzindo; e se não incluímos no fazer rede a permanente análise de seus efeitos, podemos produzir multiplicidade (muitos pontos na rede), mas sem consistência e sem sentido, produzindo dispersão. Ou seja, para que as escolas e outros serviços que compõem o sistema de proteção integral de crianças e de adolescentes operem como rede, deve-se trabalhar com a multiplicidade como ampliação da complexidade da resposta - e não como dispersão; deve-se incluir a produção efetiva de sociabilidade, laços, consistência dos vínculos; e deve-se estar atento para os efeitos de sentido e a direção ético-política produzida.

Em síntese, o agir coletivo é dimensão da experiência criançável que necessita da rede enquanto dispositivo baseado no revezamento e na alternância dos cuidados, tomada como zona de passagem e de continuidades (FUGANTI, 2009). Nessa experiência, de contração do coletivo, exercita-se o engajamento na existência em comum, processo pelo qual alguns, vários ou muitos adquirem compromissos crescentes com a existência dos outros.

\section{CONSIDERAÇÕES FINAIS}

O breve percurso sobre a posição do conflito no governo da vida de crianças e adolescentes e as vinhetas aqui dispostas apontam para algumas pistas relativas ao agir criançável: o exercício de outra concepção quanto à singularidade da infância, que escape à normalização e ao ideal e que situe o desenvolvimento como afirmação das potências de vida (CECCIM \& PALOMBINI, 2010); o multilinguismo como procedimento de positivação do precário, que implica a disposição para o imprevisto e a suspensão da rigidez das regras para a constituição de uma subjetividade que tensiona, fissura, move o instituído no sentido da expressão da ternura de um brincar necessário e vital (não só para a criança, mas para o adulto e a sociedade quando explicita sua face dogmática e opressiva, permitindo uma mudança); a sustentação das dissonâncias e dos conflitos e o exercício de contração das heterogeneidades e das diferenças; a criação de dispositivos coletivos de acolhida e sustentação coletiva da valoração afirmativa acerca da experiência da infância que nomeamos aqui de 'rede'.

Tal agir visa "libertar a criança da 'infância", "dessa interiorização das coações e dos comportamentos embrutecedores", "a pretexto de amadurecimento" (SCHÉRER, 2009, p. 35), assim como visa sustentar a polivocidade da expressão semiótica da criança.

Certamente tal ethos suscita uma necessária mudança na posição do educador/gestor/adulto no sentido da recusa a ser ele (adulto) o modelo acabado e maduro. No campo dos direitos das crianças e adolescentes, é pela ampliação dos direitos

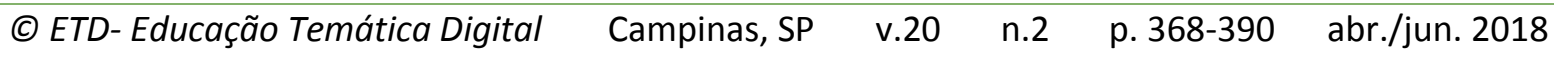


propriamente políticos, especialmente na forma de direitos de participação e de direitos de liberdade, que tal debate tem se colocado, uma vez que se reconhece que esse âmbito dos direitos contribui para ampliar a dialogia adulto-criança e para legitimar a posição da criança como ator social. Mas, como apontam Rosemberg e Mariano (2010), os direitos de liberdade dos adolescentes se veem também ressignificados pelos "limites determinados pelas políticas públicas e pelos riscos reais derivados de nós adultos e das instituições que criamos, ao impingirmos à infância uma posição de subordinação" (p. 721). De fato, sem uma análise consistente das relações de dominação, inclusive (e sobretudo, mas não exclusivamente) as etárias, declarações, estatutos ou convenções dos direitos das crianças ou mesmo dispositivos ditos participativos podem gerar mecanismos de ampliação do poder adulto (MELO, 2011). Tal ethos implica, ainda, a não "aceitação tácita da supressão ou subalternização dos direitos das crianças em condições especialmente precárias ou vulneráveis" (MARCHI \& SARMENTO, 2017), as quais se agudizam no contexto brasileiro de desigualdades sociais.

A configuração dos direitos políticos da infância passa, no caso da escola, pela sustentação do próprio campo do conflito, inerente à tarefa educativa, assim como da implicação do educador. Isto é, de sua disposição, e da escola, de se colocarem numa posição de corresponsabilidade na formulação das indagações e novas miradas, assim como das apostas que os conflitos podem suscitar. Como também já assinalava Galvão (2004), a disposição positiva diante do conflito é condição para a formulação de seus sentidos e para a não eclosão da violência. Tal disposição põe em jogo o exercício do agir comum na direção da gestão autônoma e participativa dos conflitos, assim como o exercício de que nos "desalojemos da segurança de valores supostamente protetivos, mas que desconsideram as perspectivas das próprias crianças e adolescentes" (MELO, 2011, p. 34).

\section{REFERÊNCIAS}

ALMEIDA, Pedro Rodrigues de. A pró-cura do médico de cabeça: análise da demanda por atendimento na neurologia infantil. Dissertação de Mestrado. Programa de Pós-graduação em Psicologia. Universidade Federal Fluminense, Niterói. 2017. 144 p.

ABRAMOVAY, Miriam; RUA, Maria das Graças (Coord.). Violências nas escolas. Brasília: UNESCO, 2002. 440p. Disponível em: http://unesdoc.unesco.org/images/0012/001257/125791porb.pdf Acesso em: 15/07/2017.

AQUINO, Julio Groppa. Indisciplina escolar: um itinerário de um tema/problema de pesquisa. Cadernos de Pesquisa, v. 46, p. 664-692, 2016. Disponível em: http://dx.doi.org/10.1590/198053143670 Acesso em: 20/12/2017. 
AQUINO, Julio Groppa. Indisciplina na escola: alternativas teóricas e práticas. São Paulo: Summus, 1996. 148p. ISBN: 8532305830.

ARANTES, Esther Maria de Magalhães. Direitos da criança e do adolescente: um debate necessário. Psicologia Clinica, Rio de Janeiro, v. 24, n.1, p. 45-56, 2012.

ARIÉS, Philippe. História social da criança e da família. 2.ed. Rio de Janeiro, Zahar, 1981. 279p. ISBN: 8524500360.

CALDEIRA, Teresa Pires do Rio. Cidade de muros: crime, segregação e cidadania em São Paulo. São Paulo, Editora 34/Edusp, 2000. 399p. ISBN: 8573261889.

CASTRO, Lucia Rabello de. Uma teoria da infância na contemporaneidade. Em: Castro, L. R. de (Org.). Infância e adolescência na cultura do consumo. Rio de Janeiro: NAU, 1998, 232 p.

CASTRO, Lucia Rabello de. Da invisibilidade à ação: crianças e jovens na construção da cultura. p. 19-46. Em: Castro, L. R. (Org.), Crianças e jovens na construção da cultura. Rio de Janeiro: NAU/FAPERJ, 2001, 226 p., ISBN: 9788585936471.

CECCIM, Ricardo Burg; PALOMBINI, Analice de Lima,. Imagens da infância, devir-criança e uma formulação à educação do cuidado. Psicologia \& Sociedade [Online], 21(3). Abril, 2010. Disponível: http://www.ufrgs.br/seerpsicsoc/ojs/viewarticle.php?id=714 Acesso em: 23 de julho de 2017.

CORAZZA, Sandra Mara. História da infância sem fim. Ijui: Unijui, 2000. 392 p. ISBN: 9788574291826.

CORAZZA, Sandra Mara. Infância e educação: era uma vez...quer que conte outra vez? Petrópolis: Vozes, 2002. 204p. ISBN: 9788532627612.

CONSELHO REGIONAL DE PSICOLOGIA 6a Região, Grupo Interinstitucional Queixa Escolar (Orgs.). Medicalização de Crianças e Adolescentes. Conflitos silenciados pela redução de questões sociais a doenças de indivíduos. São Paulo: Casa do Psicólogo, 2010. 344p. ISBN: 9788580405958.

DELEUZE, Gilles. Conversações. Rio de Janeiro: Ed. 34, 1992. 226p. ISBN: 8585490042.

DIÓGENES, Gloria. Cartografias da Cultura e da Violência. Gangues, galeras e o movimento Hip Hop. São Paulo, AnnaBlume; Fortaleza, Secretaria da Cultura e Desportos, 1998. 246 p. ISBN: 8574190160.

DONZELOT, Jacques. A Policia das famílias. Rio de Janeiro, Graal, 1986. 209p. ISBN: 9788570380234. 
FERENCZI, Sandór. "Confusão de língua entre adultos e crianças. A linguagem da ternura e da paixão" Em: Escritos psicanalíticos 1930-1933 (org) Joel Birman, (pp. 347-356). Rio de janeiro, Taurus. 356 p. (sem ISBN).

FOUCAULT, Michel. Em defesa da sociedade. São Paulo: Martins Fontes, 1999. 382p. ISBN: 8533610041.

FOUCAULT, Michel. Os anormais. São Paulo: Martins Fontes, 2001. 479p. ISBN: 8533614292.

FOUCAULT, Michel. O poder psiquiátrico. São Paulo: Martins Fontes, 2006. 511p. ISBN: 8533622767.

FOUCAULT, Michel. Segurança, território, população. São Paulo: Martins Fontes, 2008. 572p. ISBN: 9788533623774.

FUGANTI, Luis. Biopolítica e produção de saúde: um outro humanismo? Interface, 13(1): 667-679, 2009. Disponível em:

http://www.scielo.br/scielo.php?script=sci arttext\&pid=S1414-32832009000500017 Acesso em: 05/10/2017.

GALVÃO, Izabel. Cenas do cotidiano escolar: conflitos sim, violência não. Petrópolis: Vozes, 2004. 232p. ISBN: 9788532629401.

GONÇALVES, Luiz Alberto Oliveira e SPOSITO, Marília Pontes. Iniciativas públicas de redução da violência escolar no Brasil. Cadernos de Pesquisa 115, p. 101-138, 2002.

GRAMKOW, Gabriela. Fronteiras psi-jurídicas na gestão da criminalidade juvenil: o caso da Unidade Experimental de Saúde. Tese de doutorado. Curso de Pós Graduação em Psicologia Social, Pontifícia Universidade Católica de São Paulo, SP, 2012.

JENKS, Chris. Constituindo a criança. Educação, Sociedade e Culturas, Porto, n.17, p.185216, 2002.

LAPASSADE, Georges. La entrada en la vida. El enigma de la pubertad. Madrid, Fundamentos, 1973. 283 p. ISBN: mkt0002559669.

LISBOA, M. Os loucos de rua e as redes de saúde mental: os desafios do cuidado no território e a armadilha da institucionalização. Tese de Doutorado em Psicologia Social. Curso de Pós Graduação em Psicologia Social, Pontifícia Universidade Católica de São Paulo, SP, 2013.

LOBO, Lilia. Os infames da história. Pobres, escravos e deficientes no Brasil. Rio de Janeiro: Ed. Lamparina, 2015, 464 p. ISBN 9788583160335. 
LOURAU, René. “Mesa giratoria. Hipercomunicación adulto/niño”. Em: ACEVEDO, María José e Volnovich, Juan Carlos (orgs.). El Espacio Institucional II. Buenos Aires, Lugar Editorial, 1991. 176 p. ISBN: 950-9129-53-4.

MARCHI, Rita de Cassia. Os sentidos (paradoxais) da infância nas ciências sociais: um estudo de sociologia da infância crítica sobre a "não criança" no Brasil. Tese de Doutorado em Sociologia Política. Programa de Pós-Graduação em Sociologia Política, Universidade Federal de Santa Catarina, Florianópolis, 2007.

MARCHI, Rita de Cássia; SARMENTO, Manoel Jacinto. Infância, normatividade e direitos das crianças: transições contemporâneas. Educ. Soc., Aug. 10, 2017. Disponível em: http://dx.doi.org/10.1590/es0101-73302017175137 Acesso em: 20/12/2017.

MELO, Eduardo Resende. Direito e norma no campo da sexualidade na infância e na adolescência. In: Criança e adolescente. Direitos e sexualidades (pp. 43-56). São Paulo: ABMP e Childhood Brasil, 2008. Disponível em:

http://www.childhood.org.br/conteudo2011/Livro Crianca e Adolescente Direitos Sexual idades Reproducao.pdf . Acesso em 28/07/2017.

MELO, Eduardo Resende. Crianças e adolescentes em situação de rua: direitos humanos e justiça. São Paulo: Malheiros Editores, 2011. 142 p. ISBN 978-85-392-0024-5.

OLIVEIRA, Carmen Silveira de. Sobrevivendo no inferno. A violência juvenil contemporânea. Porto Alegre, Sulina, 2001. 256p. ISBN: 9788520502853.

ORLANDI, Luiz B. L. A inocência do devir / O devir criança do pensamento. In: SIMPÓSIO INTERNACIONAL DE FILOSOFIA: NIETZSCHE/DELEUZE, 9., 2008, Fortaleza.

Palestra...Fortaleza, 2008. Disponível em: https://goo.gl/WfxA3H. Acesso em: 20/12/2017.

ROSA, Miriam D. e VICENTIN, Maria Cristina G. Os intratáveis: o exílio do adolescente do laço social pelas noções de periculosidade e irrecuperalidade. Revista Psicologia Política, São Paulo, v. 10, n. 19, p. 107-124, jan. 2010. Disponível em:

http://pepsic.bvsalud.org/scielo.php?pid=S1519-549X2010000100010\&script=sci abstract Acesso em: 20/12/2017.

ROSEMBERG, Fulvia. Teorias de gênero e subordinação de idade: um ensaio. Pro-Posições, v.7, n.3, p.17-23, 1997.

ROSEMBERG, Fulvia; MARIANO, Carmem Lúcia Sussel. A Convenção Internacional sobre os direitos da criança: debates e tensões. Cadernos de Pesquisa, v.40, n.141, set./dez. 2010. Disponível em: http://dx.doi.org/10.1590/S0100-15742010000300003 . Acesso em: 15/07/2017.

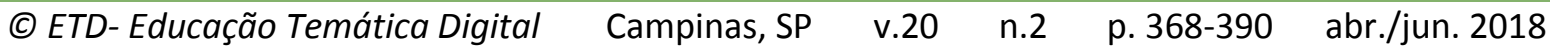


SÃO PAULO. Secretaria da Educação de São Paulo. Resolução SE no 19, de 13 de fevereiro de 2010. Institui o Sistema de Proteção Escolar na rede estadual de ensino de São Paulo e dá providências correlatas. Diário Oficial. São Paulo: Imprensa Oficial, 2010. Disponível em: http://siau.edunet.sp.gov.br/ItemLise/arquivos/19 10.HTM?Time=7/20/2012\%206:42:49\% 20AM Acesso em: 10/02/2015.

SÃO PAULO, Secretaria da Educação do Estado. Cuca Legal nas escolas. Disponível em: http://www.cucalegal.org.br/projeto cuca legal.html. Acesso em 10/02/2015.

SCHÉRER, René. Infantis. Charles Fourier e a infância para além da infância. Belo Horizonte: Autêntica, 2009. 240p. ISBN: 978-85-7526-298-6.

SCHILLING, Flávia Inês. Educação em direitos humanos: reflexões sobre o poder, a violência e a autoridade na escola. Universitas Psychologica, v.7, n.3, p.685-694, 2008.

SCHILLING, Flávia Inês. A sociedade da insegurança e a violência escolar. São Paulo: Summus, 2014. 112p. ISBN: 9788532309525.

SÃO PAULO, Secretaria da Educação do Estado. Sistema de Proteção Escolar. Disponível em http://www.educacao.sp.gov.br/spec/sobre-programa-spec/ Acesso em 10/02/2015.

SINGER, Helena. República de crianças. Sobre experiências escolares de resistência. Campinas: Mercado de Letras., 2010. 175p. ISBN: 9788575911295.

STERN, Daniel. 0 mundo interpessoal do bebê. Uma visão a partir da psicanálise e da psicologia do desenvolvimento. Artes Médicas. Porto Alegre, 1992. 276 p. ISBN:8586584738.

TEIXEIRA, Ricardo Rodrigues. O acolhimento num serviço de saúde entendido como uma rede de conversações. Em: Construção da integralidade: cotidiano, saberes e práticas em saúde. Roseni Pinheiro e Ruben Araujo de Mattos (Org.). Rio de Janeiro: IMSUERJ/ABRASCO, p.89-111, 2003. ISBN: 9788589737333.

TIBÉRIO, Welligton. A judicialização das relações escolares: um estudo sobre a produção de professores. Dissertação de Mestrado. São Paulo: Universidade de São Paulo, 2011.

VICENTIN, Maria Cristina G. "O educador bilíngüe: nas fronteiras da sexualidade e da violência”. Em: Aquino, Julio G. (Org.) Sexualidade na escola. Alternativas teóricas e práticas. São Paulo, Summus, 1997.143 p. ISBN: 8532305938.

VICENTIN, Maria Cristina Gonçalves. A vida em rebelião: jovens em conflito com a lei. São Paulo: Hucitec e Fapesp, 2005. 331p. ISBN: 9788527106825. 
VICENTIN, Maria Cristina Gonçalves. Criançar o descriançável. Em: São Paulo (SP). Secretaria Municipal de Educação. Coordenadoria Pedagógica. Núcleo de Apoio e Acompanhamento para Aprendizagem. Caderno de debates do NAAPA : questões do cotidiano escolar. - São Paulo : SME / COPED, 2016. 160p, pp. 35-43. Disponível em:

http://www.seer.ufu.br/index.php/EducacaoFilosofia/article/view/17429 . Acesso em: 20/12/2017.

WAISELFISZ, Julio Jacobo. Mapa da violência: os jovens do Brasil, 2014. Disponível em: http://www.mapadaviolencia.org.br/mapa2014 jovens.php Acesso em: 15/07/2017.

Revisão gramatical realizada por Ana Lucia Catão; email: analucatao@gmail.com. 